\title{
Chinese Agricultural Development Policies and Characteristics since the Reform and Opening up in China
}

\author{
Zhimin Lei ${ }^{1}$ \\ ${ }^{1}$ College of Politics, Sichuan Agricultural University, Chengdu, China \\ Correspondence: Zhimin Lei, College of Politics, Sichuan Agricultural University, Chengdu 611130, China. \\ E-mail: zhiminlei2007@163.com
}

Received: February 22, 2013 Accepted: March 14, 2013 Online Published: April 17, 2013

doi:10.5539/ach.v5n2p110

URL: http://dx.doi.org/10.5539/ach.v5n2p110

Sichuan province philosophy social sciences key research base of rural development research center, 2012 projects funded.

\begin{abstract}
US scholars have ever proposed the doubt of "Who will feed China?" In the past 30 years or so since the reform and opening up in China, China has fed a population accounting for more than $20 \%$ of the total population in the world with an area of cultivated land accounting for less than $10 \%$ of the total in the world. And the self-sufficiency rate of grain in China still remains above 95\%, which is an impressive achievement in Chinese agriculture, and this achievement has been a result of combined action of multiple factors. However, the most critical factor is the successful implementation of agricultural development policies by the Chinese government in the past 30 years or so ever since the reform and opening up in China.
\end{abstract}

Keywords: reform and opening up, Chinese agricultural development policies, characteristics

Ever since the reform and opening up in China, Chinese agricultural development policies have undergone more than 30 years, and from the policy of mobilizing enthusiasm of farmers to development of agriculture in the market economy and then to the policy of strengthening farmers, benefiting farmers and enriching farmers, all these policies are not only periodical, but also continuous and are constantly pushed to a higher level. The target of strengthening agricultural foundation and promoting increase in grain yield and increase in farmers' income has run through the policies for more than 30 years. Chinese agriculture has not only resolved the eating problem of Chinese people, but has also supported development and process of the Chinese economic society for more than 30 years, and has also made great contributions to China and even to the whole world.

\section{Chinese Agricultural Development Policies and Characteristics from 1978 to 1999}

The reform and opening up in China began in rural reform. From the founding of the new China until the reform and opening up, Chinese agriculture mainly relied on cooperation movement to be promoted and developed. Since people's commune system was ahead of the times, it failed to mobilize farmers' enthusiasm in production. Under such a system, Chinese farmers paced up and down and the eating problem of Chinese people was still not effectively resolved.

From the year 1978 to the end of last century, the government carried out guidelines and specific policies at a macro level and promoted modern Chinese agricultural development, increase in grain yield and increase in farmers' income with the aim of strengthening agricultural foundation, facilitating increase in grain yield and increasing farmers' income at different stages and in due time from the strategic height of the national development.

The agricultural development policies during this period could be classified into two stages. The first stage is from the year 1978 to the middle of the 80s. The Third Plenary Session of the 11th Central Committee of the Chinese Communist Party passed "The Decision (Draft) about Several Issues to Speed up Agricultural Development", which analyzed the current condition of agriculture in China at that time and summarized the historical experience and lessons in the intricate development of agriculture ever since the founding of the country. It was believed that "Whether all of our policies comply with the need of development of the productivity rests with whether these policies can mobilize the enthusiasm of laborers", and "we have to firmly 
modify and correct all those wrong measures that go against playing of farmers' enthusiasm in production and against development of agricultural productivity". (People's Daily) It is necessary to strengthen the material support and technical support of the country on agriculture to enable agriculture to obtain advanced technical equipment and to enable farmers' scientific and technical level to get gradually improved. On this basis, the "Decision" proposed a series of guidelines and polices to speed up agricultural development within two or three years, alleviate farmers' burden, increase farmers' income and develop agriculture. Thus, agricultural policy making at this stage began with fully mobilizing the enthusiasm of farmers in production, focused on the household contract responsibility system, allowed for diversified economy, developed township enterprises, enhanced rural economic quality, promoted transformation of rural industrial structure and economic structure and carried forward rapid development small towns with Chinese characteristics.

In 1980, Deng Xiaoping gave a high comment on the amazing achievement in the production contracted to each household in Anhui, and he said, "After the rural policies relaxed restrictions, the areas where the policy of production contracted to each household is suitable have carried out this policy, which has obtained a good effect and great changes have taken place. A large majority of production teams in Feixi County in Anhui Province have carried out the policy of production contracted to each household and the margin of increase in grain yield was great" (Deng, 1994, p. 315).

The second stage began from the middle of 90 s when "rural area, agriculture and farmer, namely, the "three rural issues" were planned and designed as a whole based on the periodical characteristics of rural reform and a new turn of a series of agricultural development policies were promulgated. The purpose was to gradually settle contradictions between farm households and the market under the socialism market economy and support agriculture and farmers. The characteristics was to adhere to and improve the household contract system that effectively promoted agricultural development in the first turn of reform, deepen development of township industry into an urbanization strategy, meanwhile, practically alleviate farmers' burden by means of reform of rural taxation expenses and the policy of conservation price of procurement of agricultural products and explore new mechanism and methods to promote agricultural development under the market economy from an institutional perspective.

The two turns of reform policies presented an overall progressive and deepening characteristic. Especially the second turn of reform measures and system had strong innovation, and the policies of reform of rural taxation expenses and industrialized operation of agriculture broke through some deep levels of obstacles in Chinese institutional mechanism, which laid a good foundation for promulgation of agricultural development policies at the next stage.

\section{Chinese Agricultural Development Policies and Characteristics after China Entered the New Century}

\subsection{The Historical Background of Promulgating the Chinese Agricultural Development Policies in the New Century}

At the turn of the century, agriculture and rural development in China entered a new stage when such major agricultural products as grain turned from long term shortage to overall balance of total amount and abundant and bumper harvest. However, during almost the same period, the "express train" of industrialization and urbanization took away from the rural areas a large amount of resources, such as, land, funds, and labor force, etc. Grain production was lingered and increase in farmers' income got into hot water. The rapid industrialization and urbanization proposed new requirements of accelerating transfer of agricultural development mode and development of a new type of agriculture to Chinese agriculture.

After entrance into the new century, development of Chinese agriculture also manifested a lot of new changes. Firstly, the tendency of small departmentalization appeared in agriculture and both the ratio of agricultural production value and the ratio of agricultural export were reduced a little bit. Secondly, the functions of agriculture presented a tendency of diversification. For instance, agriculture not only had the function of increasing employment, but also had the function of ecological protection, tour and relaxation and heritage of culture, etc. Under the backdrop of small departmentalization and diversified functions of agriculture, the pressure of ensuring national food security and effective supply of agricultural products was great to such a large population of China. Besides, Chinese agriculture was also faced with a series of new difficulties, such as, strengthened resource environment and market constraint, aggravated trade competition of agricultural products and reduction of comparative interest, etc. All these new problems and new changes required us to have to change the agricultural production mode and accelerate promotion of a new type of agriculture, namely, modern agricultural development, so as to face up with new challenges. 


\subsection{The Overall Requirement of Chinese Modern Agricultural Development}

From the year 2004 until the year 2012, the Central Committee of the Communist Party of China consecutively promulgated nine central NO.1 documents with the core of "the three rural issues". Especially, the central NO.1 document in 2007 with the theme of positively developing modern agriculture firmly pushed forward construction of the new socialist countryside. The Third Plenary Session of the 17th Central Committee of the Chinese Communist Party further confirmed related content and strategy of modern agricultural development. The overall requirement of Chinese modern agricultural development is as follows:

Developing the five targets of modern agriculture: high yield, high quality, high efficiency, ecology, security and optimizing variety and quality structure of agricultural products.

Promoting the six major approaches to construction of modern agriculture: to equip agriculture with modern material conditions, to reform agriculture with modern scientific technology, to enhance agriculture with modern industrial system, to facilitate agriculture with modern operation means, to direct agriculture with modern development idea and to develop agriculture with by means of cultivating a new type of agriculture.

Establishing the development direction and targets of modern agriculture. Firstly, it is to improve agricultural mechanization, irrigation and informationization level. Secondly, it is to enhance agricultural labor productivity, land output capacity and resource utility rate. Thirdly, it is to improve the risk resistance capacity, market competitive capacity and sustainable development capacity of agriculture.

\subsection{Establishment of Agricultural Development Policy System Characterized by the Policy of Strengthening Farmers, Benefiting Farmers and Enriching Farmers}

Adhering to the Guideline of Giving More, Taking Less and Loosening and Benefiting the Achievement of Development to Farmers so as to Increase Farmers' Income.

At the Second Conference of the Tenth National People's Congress which was held in March 2004, the Prime Minister Wen Jiabao announced in the government work report that, from the year 2004, "the government would, step by step, reduce agricultural tax rate and an average of 1 percentage will be reduced each year. Within five years, the agricultural tax will be rescinded." According to the preliminary statistics, exemption of the agricultural tax and cancelling of agricultural special duty except for tobacco leaf could lighten the burden of approximately 50 billion Yuan on farmers. In the year 2005, there were approximately 0.8 billion farmers who benefited from the above policies and these farmers received tangible benefits from the reform.

Enlarging Investment, Strengthening Agricultural Material Infrastructure and Attempting to Make Agricultural Foundation Stronger.

At present, agriculture is still the most fragile link in the national economy, which not only doesn't correspond to the strategic position of agriculture, but also makes construction of the new socialist countryside lacking in industrial support and affects the overall situation of economic and social development. In the face of this reality, the country has to continuously enlarge financial expense to support farmers and propose and implement a series of policies to strengthen farmers, such as, strengthening agricultural infrastructure construction, improving the overall agricultural production capacity, developing modern agriculture and strengthening agricultural basic construction, etc.

In terms of increasing investment in agriculture, the central NO.1 document in 2006 clearly specified, investment in rural and agricultural funds should adhere to the policy of "three higher", namely, increment in the national finance supporting agriculture should be higher than that in the past year, the ratio of the government loan and capital within the budget used for rural construction should be higher than that in the past year and the funds directly used to improve rural production and life conditions should be higher than that in the past year. On the basis of the document in 2006, the central NO.1 document in 2007 further emphasized, it was necessary to carry out the policy of "three continuously higher". And the central NO.1 document in 2008 further emphasized implementation of the policy of "three obviously higher". That is, increment in the national finance supporting agriculture should be obviously higher than that in the past year, increment in the fixed national capital investment in rural areas should be obviously higher than that in the past year and increment in the revenue of government land grant used for rural construction should be obviously higher than that in the past year. The central NO.1 document in 2009 clearly proposed implementation of "three increments on a large margin". The central NO.1 document in 2010 further emphasized ensuring "three superiorities". During the entire "eleventh five-year plan", investment of the central finance used for "the three rural issues" approximated to 3 trillion Yuan, which was 2.6 times more than that during the "tenth five-year plan". In 2011, investment of the central finance used for "the three rural issues" approximated to 1 trillion Yuan, which almost kept continued increase of the 
total amount and steady increase of the proportion.

In terms of agricultural infrastructure construction, in order to enhance production conditions of agriculture and improve the overall production capacity of agriculture, in the past few years, agricultural infrastructure construction was strengthened mainly through construction of water conservancy works, construction of wood and forest ecology, construction of cultivated land quality and promotion of agricultural mechanization.

In terms of agricultural scientific service, firstly, it is to grasp agricultural scientific research, especially cultivation of improved varieties as the focus of agricultural scientific innovation. Secondly, it is research and development of new technology and new variety. Thirdly, it is to concentrate on application of new varieties and new technology and implementation of the project of agricultural technology entering households. In 2012, the Central Committee of the Communist Party of China promulgated "Several Opinions about Accelerating Promotion of Agricultural Scientific Innovation and Continuously Strengthening Supply Security Capacity of Agricultural Products". A series of policies to strengthen farmers, benefit farmers and enrich farmers firmly grasped the burgeoning historical opportunities of world scientific revolution, adhered to the strategy of boosting agriculture and strengthening agriculture with science and technology, broke through institutional obstacles of the system, increased investment in agricultural science and technology on a large margin, facilitated great-leap-forward development of agricultural science and technology and infused strong power for Chinese agricultural increase in production, increase in farmers' income and rural prosperity.

In terms of construction of the circulation system, on one hand, construction of rural circulation facilities was focused, and on the other hand, construction of market system for agricultural products was strengthened. Meanwhile, a multi-channel market was fostered. In construction of the circulation facilities, infrastructure construction was strengthened in terms of storage and transportation.

In terms of agricultural construction adjustment, in order to construct an agricultural industrial system, a basic idea about structural adjustment was proposed to optimize product variety, optimize structure and optimize product pattern. At the same time, an agricultural operation mode was put forward to develop and economize agriculture, circular agriculture and ecological agriculture. In the meantime, construction of modern agricultural demonstration park area was made to develop agricultural industrialization, develop deep processing of agricultural products, promote funds, technology and elements to concentrate towards the park area and improve the scale and level of agricultural operation.

In terms of innovating agricultural operation mode, it was emphasized to stabilize and improve household contract management, and, meanwhile, explore new agricultural operation modes on the basis of the household contract management, such as, development of farmers' specialized cooperative and development of agricultural socialization service, etc. According to the decision made on the Third Plenary Session of the 17th Central Committee of the Chinese Communist Party, the requirement of two changes was put forward to further innovate and improve the operation situation of agriculture.

The above six aspects of increasing investment in agriculture, increasing agricultural subsidy, strengthening agricultural infrastructure construction, improving scientific service of agriculture, strengthening construction of rural circulation market system, adjusting and optimizing agricultural structure and promoting innovation of agricultural operation mode became the major policies and measures to promote construction of modern agriculture. All these policies and measures faced up to lagging and disadvantages in agricultural infrastructure and seized the sources for all kinds of difficulties encountered in the current agriculture.

The national agricultural policies during the new period changed from supporting farmers and benefiting farmers to strengthening farmers and enriching farmers. The policy of supporting farmers and benefiting farmers is more advanced than the policy of lightening the burden on farmers, which has effectively increased income of farmers, satisfied their interest and mobilized their enthusiasm in farming.

The Prime Minister Wen Jiabao mentioned in his summary of the government work in the past five years in the government work report in 2008, for the first time, the area of our agricultural food production, the total production output and per unit yield increased for consecutive four years and rural per capita net income also, for the first time, increased by more than 200 Yuan each year for consecutive four years. In 2007, rural per capita net income attained 4140 Yuan, which increased by $9.5 \%$ compared with the year 2006 by deducting the Consumer Price Index and this was the year in which farmers' income increased the most ever since 1997.

With the support of the government and with positive efforts of the market subject, development of Chinese modern agriculture has achieved great leap and has also accumulated some basic experiences for success of development. That is, the government persistently believes in the basic idea that agriculture the priority among 
all priorities in the national economy, adheres to the basic strategy of balancing urban and rural development, persists in the national strategy of giving more, taking less, loosening, industry feeding back agriculture and urban area supporting rural areas in the policy of strengthening farmers, benefiting farmers and enriching farmers, and sticks to enlarging continuous and effective investment in agriculture, farmers and rural areas.

All these basic experiences will be supported, strengthened and improved in the "twelfth five-year plan", further intensify financial investment in supporting agriculture, further strengthen the work on the three rural issues and promote further development of Chinese modern agriculture. It is generally believed that, Chinese agricultural development experience and development policies will provide reference for development of modern agriculture in other countries, especially developing countries and make greater contributions for peaceful development of the world.

\section{References}

Deng, X. (1994). Collected Works of Deng Xiaoping (Vol. 2, p. 315). People's Publishing House.

Ministry of Education. (2007). To Bring Rural Compulsory Education into the Scope of Insurance Coverage of Public Finance. Retrieved February 27, 2007, from http://news.sohu.com/

The Decision (Draft) about Several Issues to Speed up Agricultural Development. People's Daily, December 24, 1978. 